Supporting Information

\title{
Characteristics of High Efficiency Dye-sensitized Solar Cell
}

\author{
Qing Wang ${ }^{\text {a }}$, Seigo Ito ${ }^{\text {a }}$, Michael Grätzel ${ }^{\text {a }}$, \\ Francisco Fabregat-Santiago ${ }^{b}$, Iván Mora-Seró ${ }^{\mathrm{b}}$, Juan Bisquert $^{\mathrm{b}}$
}

Takeru Bossho ${ }^{\mathrm{a}, \mathrm{c}}$ and Hachiro Imai ${ }^{\mathrm{c}}$

${ }^{a}$ Laboratory for photonics and interfaces, Institute of Chemical Sciences and Engineering, Ecole

Polytechnique Fédérale de Lausanne, 1015 Lausanne, Switzerland.

${ }^{\mathrm{b}}$ Departament de Ciències Experimentals, Universitat Jaume I, 12071 Castelló, Spain

${ }^{c}$ Environmental Material Laboratory, Material Science of Engineering, Graduate School of Engineering, Shibaura Institute of Technology 3-9-14, Shibaura, Minatoku, Tokyo, Japan, 1088548

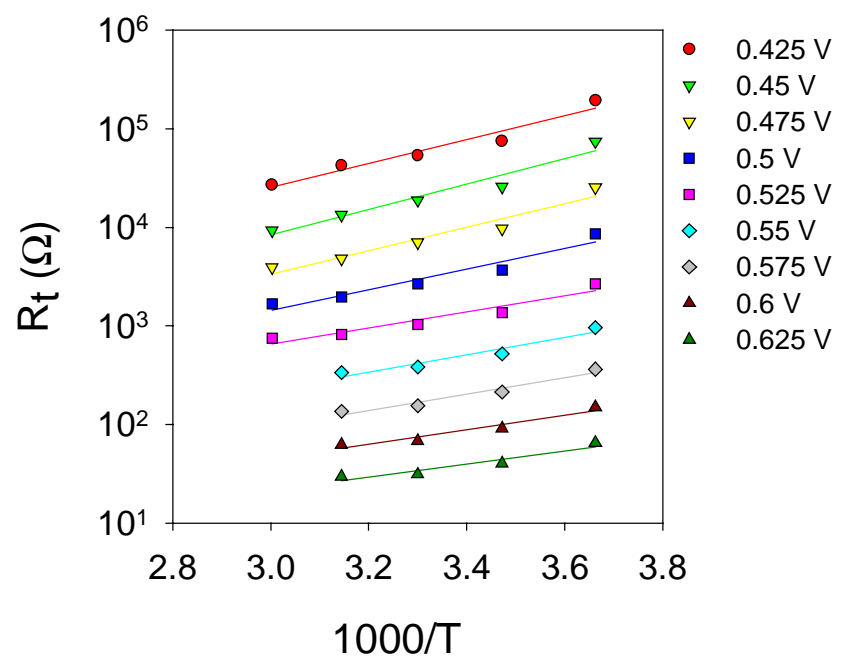

(A)

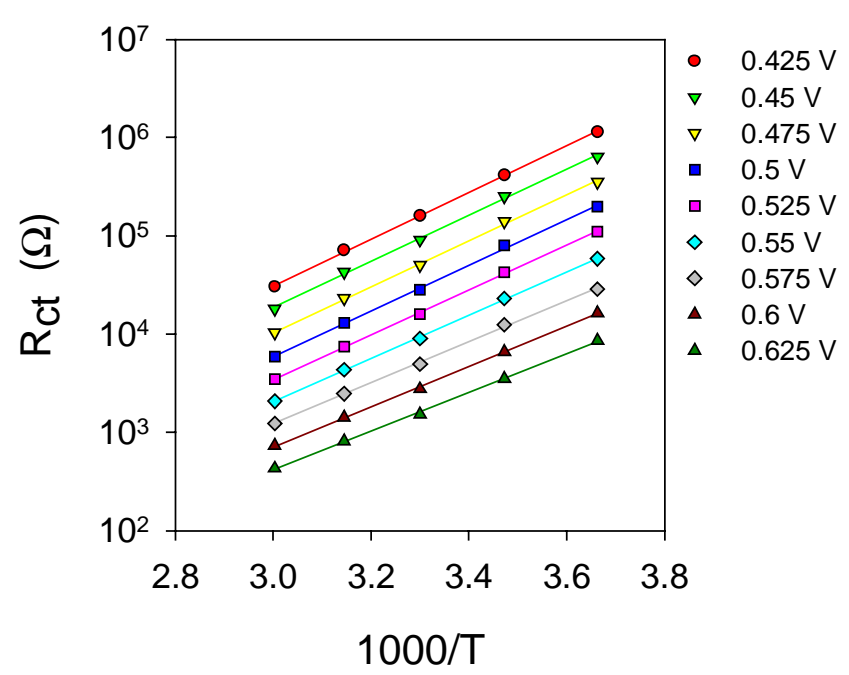

(B)

Figure S1. Arrhenius plots of the electron transport resistance $R_{t}(\mathrm{~A})$ and recombination resistance $R_{c t}(\mathrm{~B})$ of cell $\mathbf{A}$ at various bias potentials. 
Supporting Information

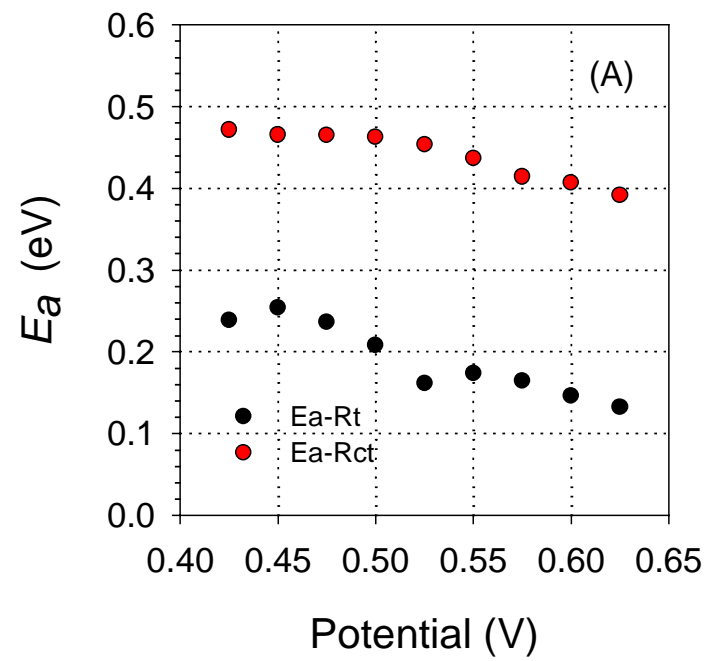

Figure S2. Activation energies of electron transport and recombination obtained from $R_{t}$ and $R_{c t}$ at different potentials. 